\title{
Simulation Strategy for the Evaluation of Neutronic Properties of a Canadian SCWR Fuel Channel
}

\author{
G. Harrisson and G. Marleau \\ Institut de Génie Nucléaire, École Polytechnique de Montréal, P.O. Box 6079, Stn. CV, Montréal, QC, Canada H3C 3A7 \\ Correspondence should be addressed to G. Harrisson; genevieve.harrisson@polymtl.ca
}

Received 20 November 2012; Accepted 8 January 2013

Academic Editor: Hangbok Choi

Copyright (C) 2013 G. Harrisson and G. Marleau. This is an open access article distributed under the Creative Commons Attribution License, which permits unrestricted use, distribution, and reproduction in any medium, provided the original work is properly cited.

The Canadian Supercritical-Water-Cooled Reactor (SCWR) is a vertical pressure tube reactor cooled with supercritical light water and moderated with heavy water. For normal operation, the local conditions of the coolant (density and temperature) and fuel (temperature) vary substantially along the channel. This means that to simulate adequately the behavior of the core under operating conditions or for anticipated accident scenario, expensive 3D transport calculations for a complete fuel channel are required. Here, we propose a simulation strategy that takes into account axial variations of the local conditions and avoids $3 \mathrm{D}$ transport calculations. This strategy consists in replacing the $3 \mathrm{D}$ simulation by a series of isolated $2 \mathrm{D}$ calculations followed by a single $1 \mathrm{D}$ simulation. It is shown that this strategy is efficient because the axial coupling along the fuel channel is relatively weak. In addition, the neutronic properties of a channel with axial reflector can be modeled using a simplified 3D transport calculation.

\section{Introduction}

The Canadian Supercritical-Water-Cooled Reactor (SCWR) is a pressure-tube type generation-IV reactor [1] based on CANada Deuterium Uranium (CANDU) reactors [2]. The preliminary concept uses a calandria vessel containing the low-pressure moderator and the five meters long fuel channels [3]. This concept uses off-power batch refueling, and to simplify the fuelling process, the reactor core is oriented vertically. Another feature of this concept is that the coolant is forced vertically downwards; that is, the coolant enters the fuel channels at the top and exits at the bottom of the core.

According to the pressure-temperature phase diagram for water, most of the current reactors operate in the liquid phase or on the saturation line. However, the main characteristic of the Canadian SCWR is that the coolant (light water) operates at pseudocritical and supercritical conditions, that is, at pressures and temperatures above the critical point of water $\left(22.064 \mathrm{MPa}\right.$ and $\left.373.95^{\circ} \mathrm{C}\right)$. The preliminary concept has a pressure of $25 \mathrm{MPa}$, a reactor inlet temperature of $350^{\circ} \mathrm{C}$ and a reactor outlet temperature of $625^{\circ} \mathrm{C}$. Figure ?? shows the expected coolant conditions along a fuel channel.

Light water has an impact on neutron slowing down and on neutron absorption. The importance of this impact depends on the temperature and on the density of this water [4]. The effect of the large variation of the coolant conditions along a fuel channel on the global neutronic properties should be studied in details, as done recently in some studies $[5,6]$.

During the optimization phase of the lattice cell of a new reactor, several neutronic transport calculations are done. Usually, these calculations are performed using deterministic codes such as WIMS-AECL [7] and DRAGON [8] for a single $2 \mathrm{D}$ lattice cell with average core conditions or with the average conditions in the region of the core that produces the highest power. However, in the case of the Canadian SCWR, this methodology is not directly applicable because the metrics (such as the exit burnup and the reactivity coefficients) used to perform the optimization depend strongly on the set of conditions found along a fuel channel. For example, Figure 2 shows the coolant void reactivity (CVR) along a fuel channel as obtained from a series of 2D infinite lattice cell calculations using the Monte Carlo code SERPENT [9] (14 independent calculations) where

$$
\text { CVR }(\mathrm{mk})=1000 \times\left(\frac{1}{k_{\text {eff }}^{\text {cooled }}}-\frac{1}{k_{\text {eff }}^{\text {vided }}}\right) \text {. }
$$




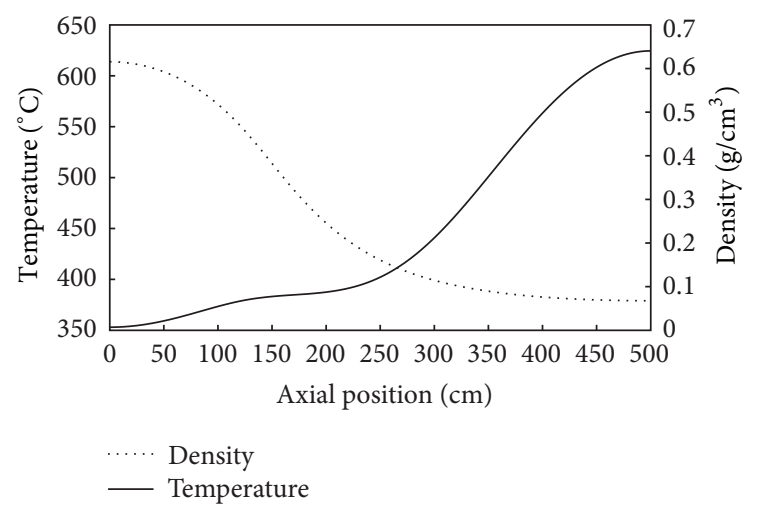

FIGURE 1: Expected coolant conditions along a Canadian SCWR fuel channel.

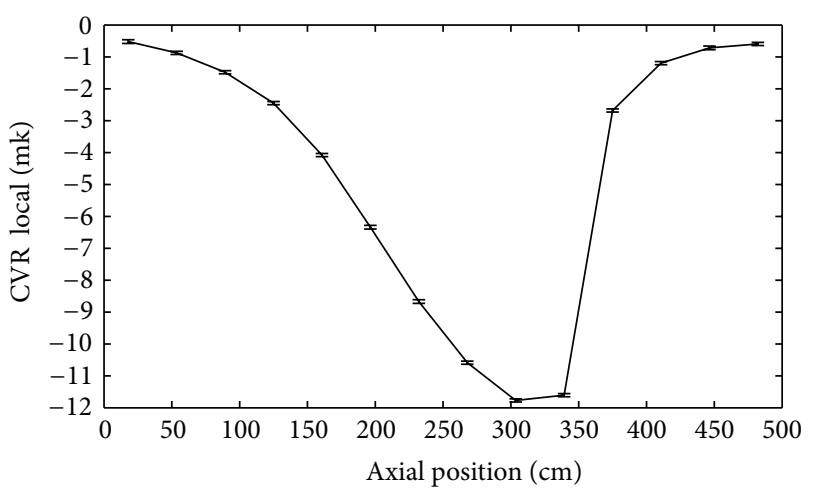

FIGURE 2: CVRs along a fuel channel obtained from independent 2D lattice cell calculations.

Here, $k_{\text {eff }}^{\text {cooled }}$ corresponds to cell calculations performed with the coolant at the expected density and temperature associated with the axial position considered in the channel, and $k_{\text {eff }}^{\text {voided }}$ is for cell calculations with the coolant absent.

The objective of this study is to establish an efficient simulation strategy that will be able to retain the simplicity and efficiency of deterministic 2D lattice cell calculation while correcting the resulting few groups reactor cross sections using a $1 \mathrm{D}$ multigroup transport model. As a result, one should be able to avoid the repetitive and computationally intensive $3 \mathrm{D}$ calculations that would be required during the optimization and operation of the core. Here we will develop and validate our simulation strategy using SERPENT to perform all $3 \mathrm{D}$ and $2 \mathrm{D}$ continuous energy simulations and DRAGON for all 1D multigroup simulations. All simulations with SERPENT have been performed with 100000 neutrons per cycle, 2000 active cycles and 200 inactive cycles. This leads to a total of 200000000 histories. The meshing used in DRAGON simulations is mentioned where appropriate in the paper.

In Sections 2 and 3, respectively, we describe and then validate the new simulation strategy proposed for fuel cells

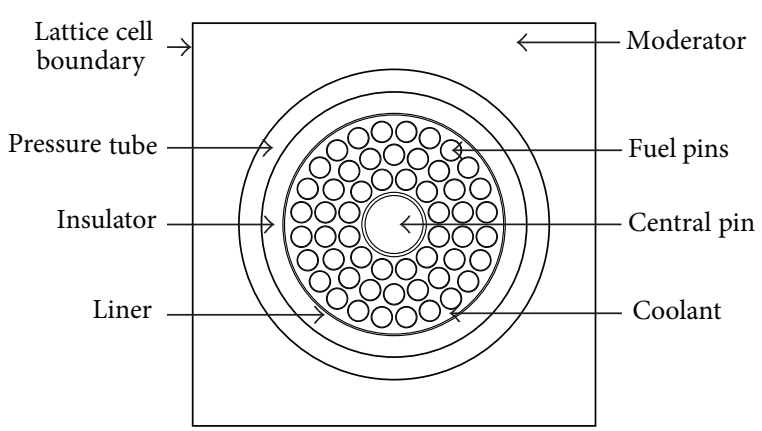

FIGURE 3: Canadian SCWR 54 elements fuel bundle and high efficiency fuel channel.

that are not in direct contact with an axial reflector cell. In Section 4, we extend the strategy to axial reflector cells and fuel cells in contact with that reflector. Finally, in Section 5 we conclude.

\section{Simulation Strategy Model for Fuel Channels without Axial Reflector Cells}

The lattice cell considered here consists of a 54 elements fuel bundle inserted in a high efficiency fuel channel [10] as shown in Figure 3.

In this design, the channel is composed of a stainless steel liner followed by an insulator of zirconia and of a pressure tube made of a zirconium alloy. The fuel is a mixture of thorium and plutonium. The central pin is filled with light water. Light water is used as coolant and heavy water as moderator. The lattice pitch is set to $25 \mathrm{~cm}$.

Even if alternative fuel bundle designs have been proposed recently [11], the specifications used in this study are based on those used in previous publications $[4,12]$ in order to facilitate comparisons with other related studies $[13,14]$.

2.1. Simulation Strategy Model. The simulation strategy proposed is based on the following hypothesis: A 3D calculation is equivalent to a series of independent $2 \mathrm{D}$ calculations followed by a single $1 \mathrm{D}$ calculation.

As shown in Figure 4, the first step of the simulation strategy proposed consists in performing a series of independent 2D infinite lattice cell calculations at strategic positions along the fuel channel.

The various levels of gray indicate that each lattice cell has a unique set of temperatures (fuel and coolant) and densities (coolant) according to the conditions expected along a fuel channel. In the next subsection, it will be shown that 14 2D infinite lattice cell calculations must be performed in this first step in order to meet the convergence criteria. For each $2 \mathrm{D}$ cell, the objective here is to determine the flux distribution $\phi$ in the $x-y$ plane and then to perform a spatial homogenization over the entire lattice cell containing $N$ regions and an energy condensation into the desired number of energy groups (the group $g$ contains the neutrons having energies between $E_{g}$ and $\left.E_{g-1}\right)$ to obtain the multigroup 


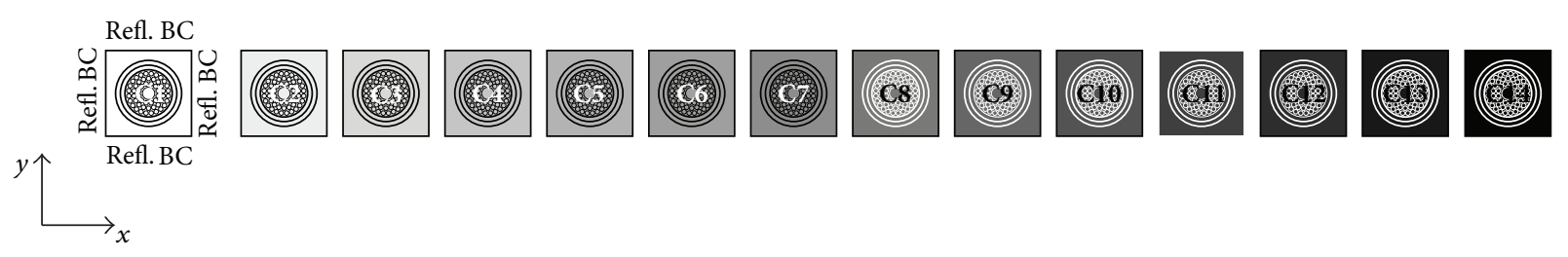

FIGURE 4: First step of the simulation strategy: 2D infinite lattice cell calculations.

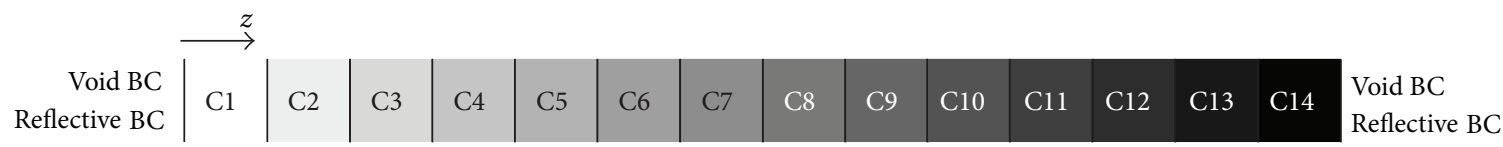

FIGURE 5: Second step of the simulation strategy: 1D slab geometry calculation.

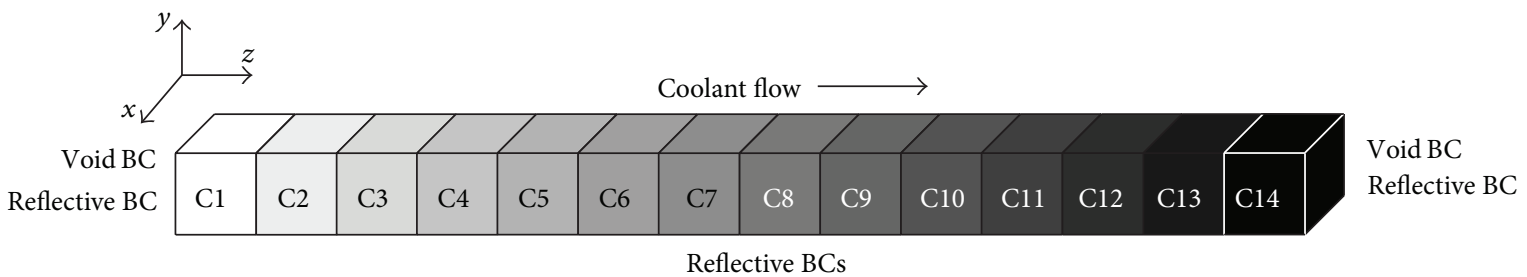

FIGURE 6: 3D reference model without axial reflector cells.

macroscopic cell averaged cross sections at each strategic position as follows:

$$
\begin{gathered}
\phi_{g}=\frac{1}{V} \int_{E_{g}}^{E_{g-1}} \sum_{i=1}^{N} \phi_{i}(E) V_{i} d E, \\
\Sigma_{g}=\frac{1}{V \phi_{g}} \int_{E_{g}}^{E_{g-1}} \sum_{i=1}^{N} \phi_{i}(E) V_{i} \Sigma_{i}(E) d E,
\end{gathered}
$$

where $V$ is the volume of the lattice cell. Reflective boundary conditions (BCs) have been applied on all outer surfaces. Here for consistency with the 3D reference model presented in Section 2.2, our 2D calculations have been performed with SERPENT.

As shown in Figure 5, the second step of the simulation strategy proposed is to perform a $1 D$ slab geometry calculation using the multigroup cell averaged cross sections calculated in the first step. This time, the objective is to obtain the flux distribution along the fuel channel. Void or reflective BCs can be applied along the axial direction, depending on the case studied. The 1D calculations were performed with DRAGON, since SERPENT cannot perform multigroup calculations. The DRAGON calculations were performed using the collision probability method with a maximum of 10 regions per cell along the $z$-axis for a maximum of 140 flux calculation regions.

By going through these two simple steps, it is then possible to simulate a $3 \mathrm{D}$ fuel channel and to obtain its averaged properties without having to do a complete $3 \mathrm{D}$ calculation.
2.2. 3D Reference Model without Axial Reflector Cells. To ensure the validity of the simulation strategy proposed, it has been compared to a complete $3 \mathrm{D}$ fuel channel calculation (Figure 6) that takes into account all temperatures and densities axial profiles in a single calculation.

Each 3D cell has a unique set of temperatures and densities according to the expected conditions along the fuel channel. At this point, one can note that the $142 \mathrm{D}$ cells presented above represent a slice of each 3D cell. The objective here is to calculate the multigroup cross sections associated with the fuel channel in a single calculation. Reflective BCs have been applied in the radial direction, and void or reflective BCs have been applied in the axial direction. All 3D calculations have been performed with SERPENT.

A study, performed with SERPENT, was conducted to optimize the number of $3 \mathrm{D}$ cells required to simulate adequately the complete fuel channel. For example, Figure 7 shows the multiplication factor of the $3 \mathrm{D}$ channel as a function of the number of 3D cells. A minimum of 2 and a maximum of $643 \mathrm{D}$ cells have been simulated. Since the results begin to converge at $143 \mathrm{D}$ cells, there is no need to increase the axial discretization further. This axial discretization leads to a maximum deviation of $0.1 \mathrm{mk}$ from the converged value obtained with 64 3D cells.

2.3. Models Comparison. Table 1 presents a comparison of the multiplication factors and CVRs obtained from the 3D reference model without axial reflector cells (SERPENT 3D) and the simulation strategy model (SERPENT 2D + DRAGON 1D). Here, two situations were considered: (1) reflective axial 
TABLE 1: Channel multiplication factors and CVRs for models without axial reflector cells.

\begin{tabular}{|c|c|c|c|}
\hline Model & $k_{\mathrm{eff}}^{\text {cooled }}$ & $k_{\mathrm{eff}}^{\text {voided }}$ & CVR (mk) \\
\hline & \multicolumn{3}{|c|}{ Reflective axial BCs } \\
\hline $\begin{array}{l}\text { Reference } \\
\text { without } \\
\text { reflector cells }\end{array}$ & $1.21712 \pm 0.00004$ & $1.20923 \pm 0.00005$ & $-5.36 \pm 0.06$ \\
\hline \multirow[t]{2}{*}{ Strategy } & 1.21711 & 1.20925 & -5.34 \\
\hline & \multicolumn{3}{|c|}{ Void axial BCs } \\
\hline $\begin{array}{l}\text { Reference } \\
\text { without } \\
\text { reflector cells }\end{array}$ & $1.21207 \pm 0.00004$ & $1.19808 \pm 0.00005$ & $-9.63 \pm 0.06$ \\
\hline Strategy & 1.21195 & 1.19808 & -9.55 \\
\hline
\end{tabular}

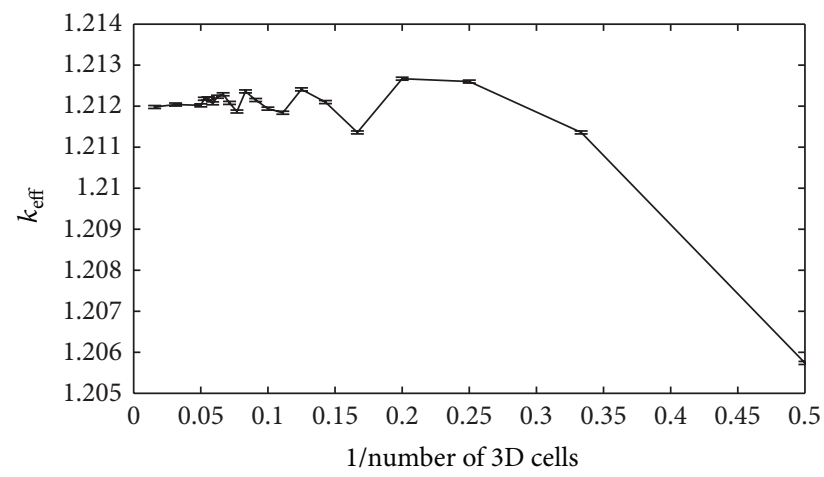

Figure 7: Optimization of the number of 3D cells in the channel.

BCs where the neutrons reaching the boundary of cells $\mathrm{Cl}$ and C14 are reflected and (2) void axial BCs where the neutrons leaving cells $\mathrm{Cl}$ and $\mathrm{C} 14$ respectively in the $-z$ and $+z$ directions are lost.

As one can see, the differences between the 3D reference model and the simulation strategy model are very small (maximum of $0.12 \mathrm{mk}$ or $3 \sigma$ ). One can also observe that the CVR is much larger in absolute value for the case where zero incoming flux boundary conditions are considered (void BCs). This may be explained in part by the fact that the effective multiplication constant is reduced. However, the main effect here is that neutron streaming without collisions through the channel along directions nearly parallel to the $z$-axis will be lost when void BCs are considered, while they will be reflected in the geometry and get a second chance to be slowed down in the moderator when reflective BCs are considered, thereby leading to a smaller absolute value of the CVR.

Overall, the simulation strategy proposed shows good agreement with the 3D reference model because the axial coupling along the fuel channel is relatively small.

\section{Assessment of the Axial Coupling}

We have assessed the extent of the axial coupling in a previous publication [15]. The main elements of this study

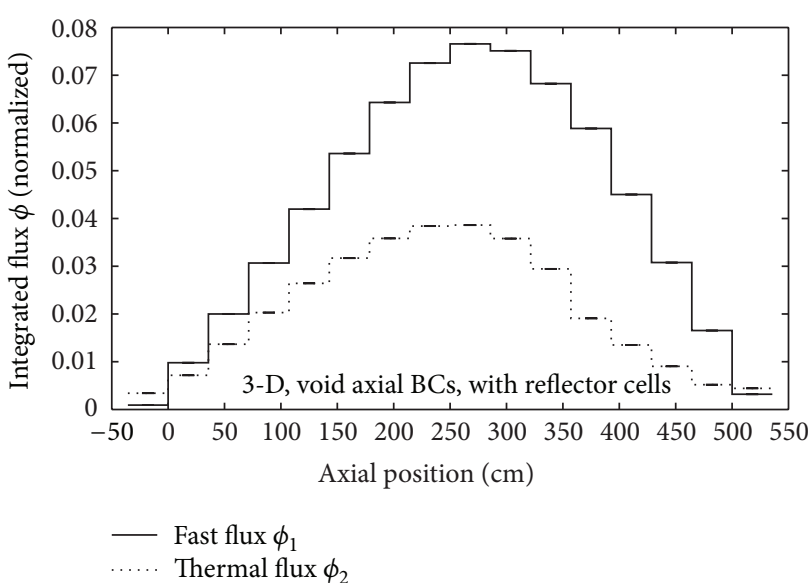

FIGURE 8: Integrated flux for a 3D fuel channel with reflector cells and void axial BC.

are presented here simply to demonstrate why the simulation strategy proposed is effective in the present case.

The physical process behind the axial coupling is described here from a simple example. Imagine two 3D cells. Taken individually, each cell has its own neutron spectrum. This spectrum is defined by the geometry and by the local conditions found in the cell. If these two cells are in direct contact, the neutrons are free to travel from one cell to the other. This exchange of neutrons between the cells can modify the neutron spectrum in them. As can be seen in (2), this shift in spectrum can lead in the end to different multigroup macroscopic cell averaged cross sections because flux levels may be different for a given energy and because the microscopic cross sections depend on the energy. However, if the cells are isolated from each other during the calculation, this exchange of neutrons cannot be taken into account [16].

With the aim to clarify the physical process involved in the axial coupling, it is relevant to take a look at the flux distribution along the fuel channel. Figure 8 presents the SERPENT calculated integrated flux (fast flux $\phi_{1}$ above $0.625 \mathrm{eV}$ and the thermal $\phi_{2}$ flux below this limit) along a 3D fuel channel with reflector cells at both ends (see Figure 9) and void axial BCs.

As one can observe, $\phi_{1}$ is slightly shifted toward the second half of the channel, while $\phi_{2}$ is more shifted toward the first half. Thus, the differences between these fluxes are significantly higher in the second half than in the first half of the channel. This effect is mainly due to the variation of the coolant conditions along the fuel channel. Since the coolant density decreases along the fuel channel, it contributes less to neutrons slowing down (decrease of $\phi_{2}$ ) leaving them at a higher energy (increase of $\phi_{1}$ ). Also, an inversion of population is observed in the reflector cells (axial positions $<0 \mathrm{~cm}$ and $>500 \mathrm{~cm}$ ), since these cells are mainly composed of moderating materials (the reflector cell is similar to a standard cell with the fuel bundle removed (see Section 4.1)).

Figure 10 presents the integrated flux ratio $\left(\phi_{1} / \phi_{2}\right)$ along the fuel channel for four different models studied with SERPENT (models description are given in Section 3.1). The 


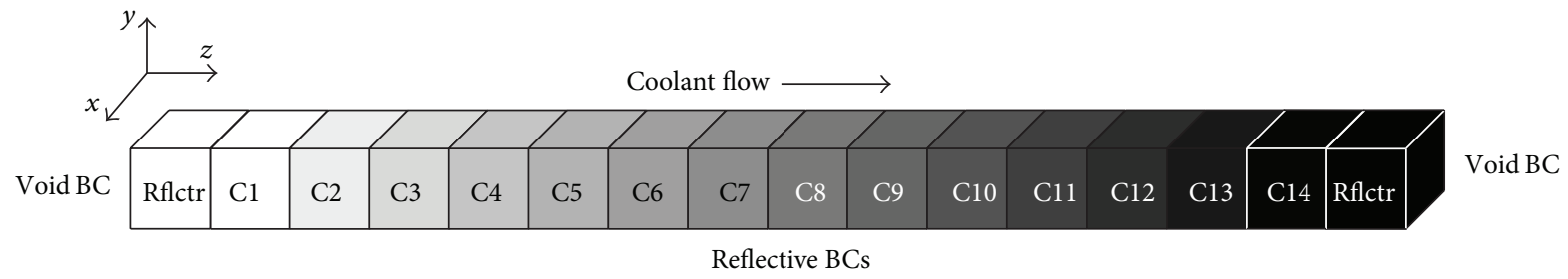

FIGURE 9: 3D fuel channel with axial reflector cells at both ends.

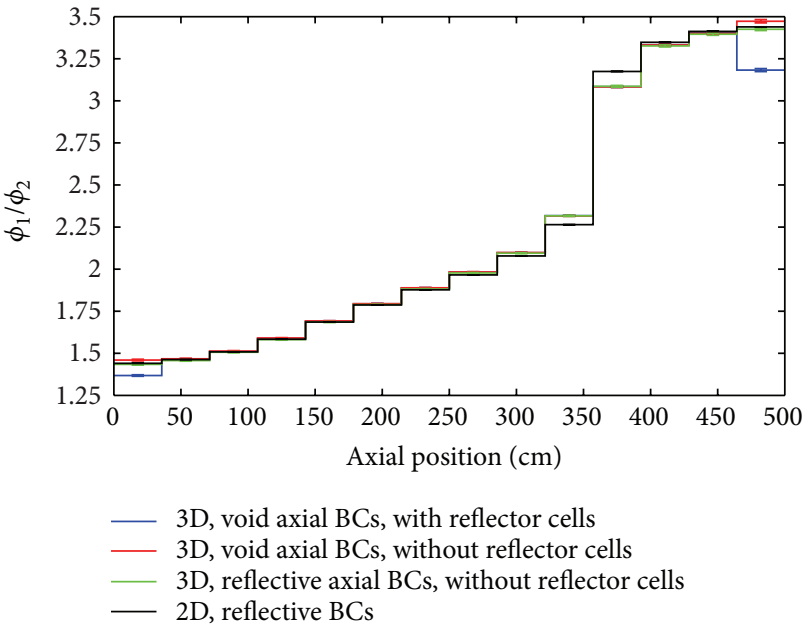

Figure 10: Integrated flux ratios for different models.

integrated flux ratio gives an indication on the distribution of the neutrons between the energy groups. Thus, the comparison of integrated flux ratios is in fact a simple comparison of neutron spectra. Here, the ratios obtained from the 3D models must be compared to those obtained from the $2 \mathrm{D}$ model. Larger differences between these ratios indicate a higher axial coupling. According to Figure 10, the differences between 3D and 2D ratios remain small for almost the entire length of the channel with a few exceptions, namely, between 325 and $375 \mathrm{~cm}$ where the CVR changes abruptly and at both ends of the channel.

While this figure describes the "flux level" component of the axial coupling, Figures 11, 12, 13, 14, 15, and 16 present a more global assessment of the axial coupling because they compare the multigroup macroscopic cell averaged cross sections where the local cell properties are also taken into account.

3.1. Approach Followed. The axial coupling has been evaluated by comparing, along the fuel channel, the multigroup macroscopic cell averaged cross sections obtained from the $3 \mathrm{D}$ models to those obtain from the $2 \mathrm{D}$ model. The absorption, up and down scattering, and fission neutron production cross sections have been studied. The cross sections have been condensed to two energy groups (fast and thermal) and homogenized over each cell [17]. The models analyzed with SERPENT are as follows.

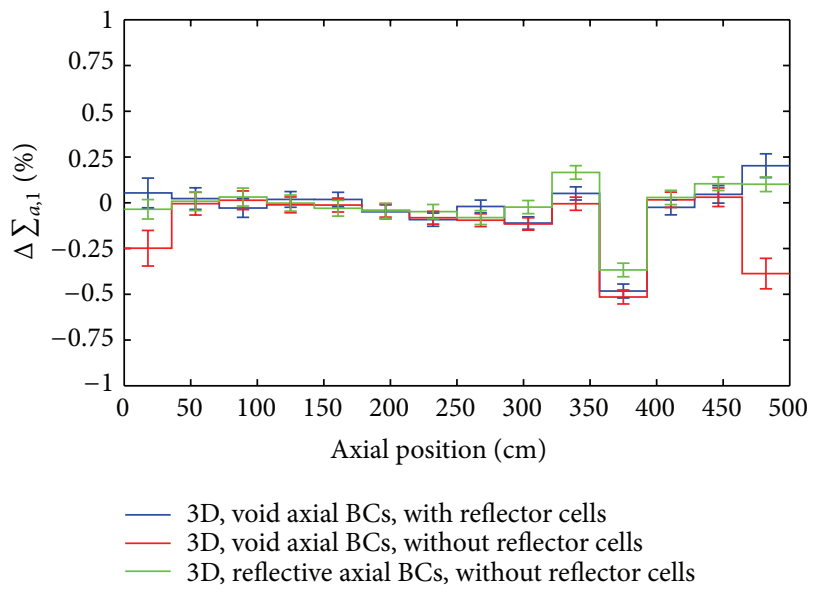

FIGURE 11: Relative differences between absorption cross sections for the fast group.

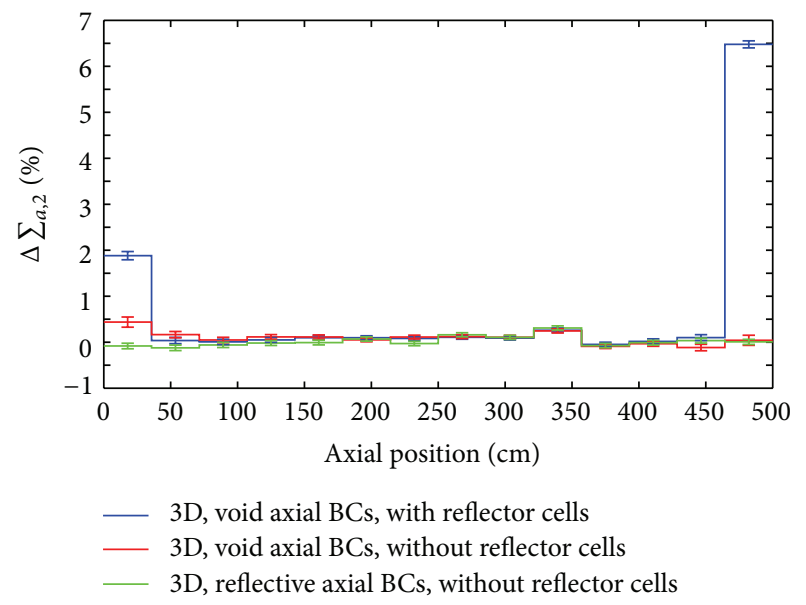

FIGURE 12: Relative differences between absorption cross sections for the thermal group.

(i) A 3D fuel channel with reflector cells at both ends assuming reflective $\mathrm{BCs}$ in the radial direction and void BCs in the axial direction (Figure 9).

(ii) A 3D fuel channel without reflector cells assuming reflective $\mathrm{BCs}$ in the radial direction and void BCs in the axial direction (Figure 6). 


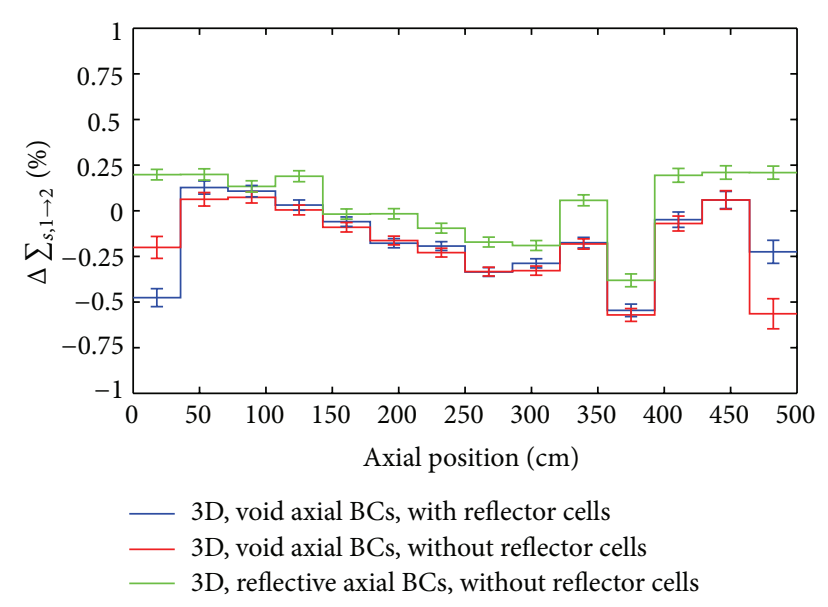

Figure 13: Relative differences between down scattering cross sections.

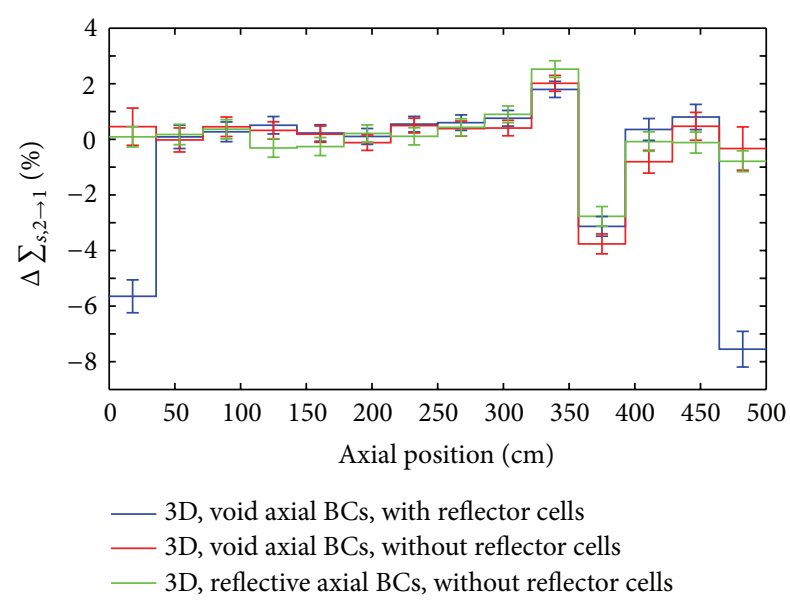

FIGURE 14: Relative differences between up scattering cross sections.

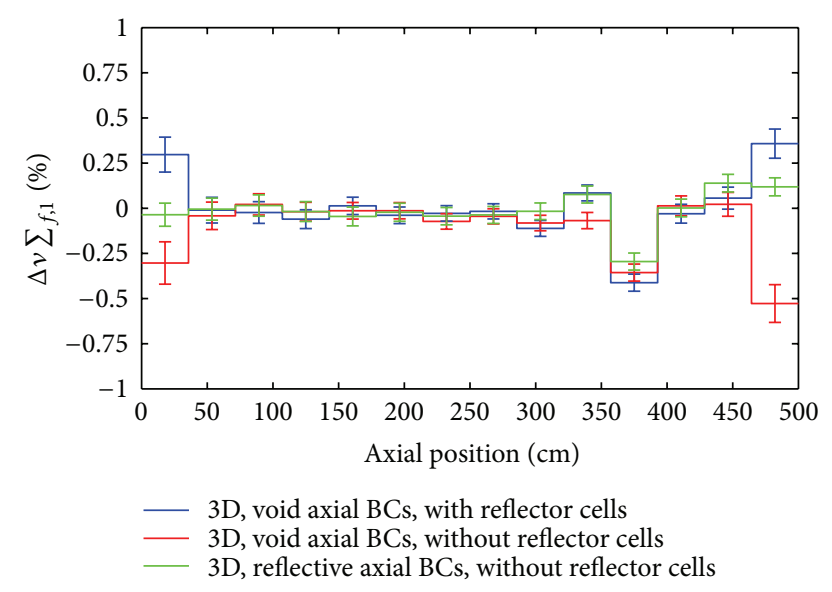

FIGURE 15: Relative differences between fission neutron production cross sections for the fast group.

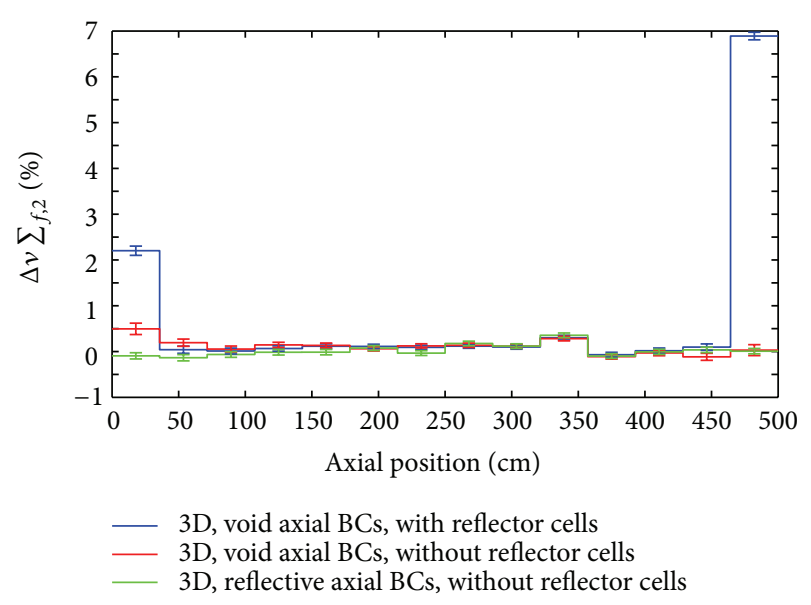

FIGURE 16: Relative differences between fission neutron production cross sections for the thermal group.

(iii) A 3D fuel channel without reflector cells and with reflective BCs in all directions (Figure 6).

(iv) $142 \mathrm{D}$ cells with reflective BCs (Figure 4).

3.2. Multigroup Macroscopic Cell Averaged Cross Sections Evaluations. Figures 11-16 present the relative differences between multigroup macroscopic cell averaged cross sections calculated as follows:

$$
\Delta \Sigma_{x, g}(\%)=100 \times\left(\frac{\Sigma_{x, g}^{3 \mathrm{D}}-\Sigma_{x, g}^{2 \mathrm{D}}}{\Sigma_{x, g}^{3 \mathrm{D}}}\right),
$$

where the $3 \mathrm{D}$ and $2 \mathrm{D}$ superscripts refer, respectively, to one of the 3D models and to the 2D model while the subscripts $x$ and $g$ refer, respectively, to the reaction type and the energy group.

Overall, differences below $\pm 0.6 \%$ are observed in the central region of the channel. However, differences can rise up to about $\pm 7.5 \%$ at channel ends, where the effects of the reflector cells on the multigroup cell averaged cross sections are mainly observed. This investigation demonstrates that the axial coupling along the fuel channel appears to be small compared to the effects of the reflector cells.

\section{Extended Simulation Strategy for Fuel Channels with Axial Reflector Cells}

Two problems arise when a 3D fuel channel with axial reflector cells has to be reconstructed from a series of independent 2D lattice cell calculations: (1) the multigroup cell averaged cross sections in fuel cells adjacent to the reflector cells are not well approximated by independent 2D lattice cell calculations, as pointed out in the previous section, but more importantly (2) the multigroup cell averaged cross sections in the reflector cells cannot be calculated from a single cell containing only moderator materials because it is not possible to perform a neutron transport calculation without neutron sources and without incoming neutron fluxes. 

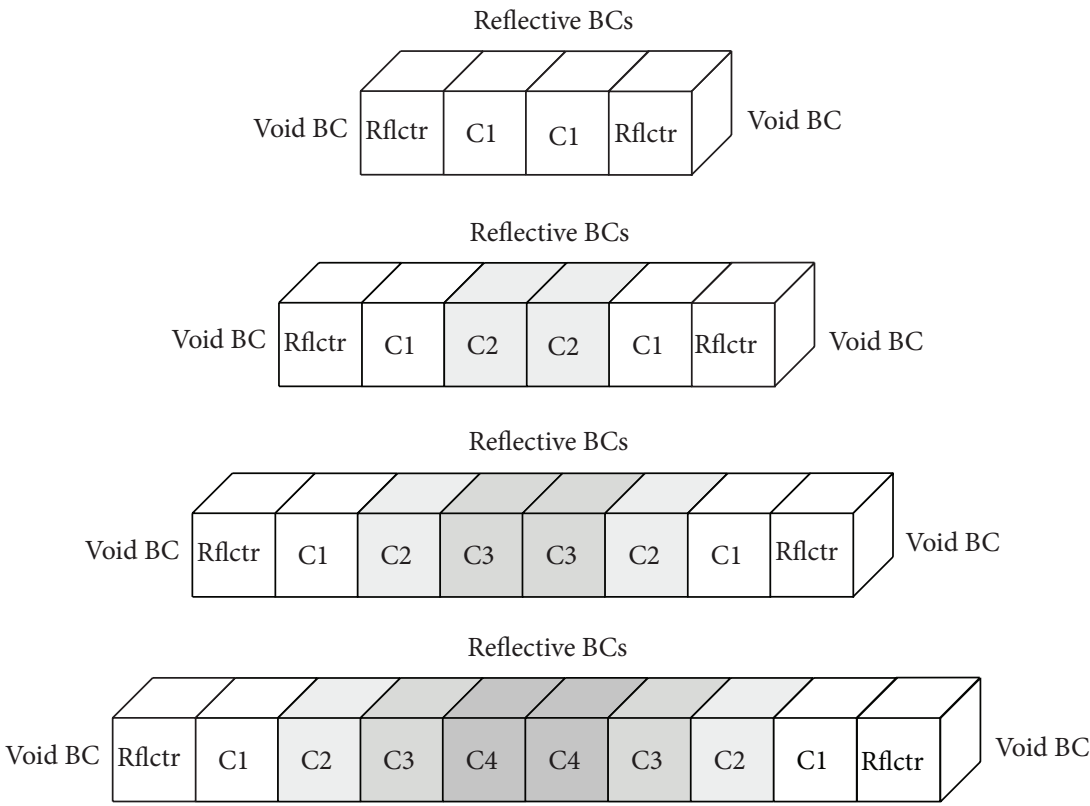

Reflective BCs
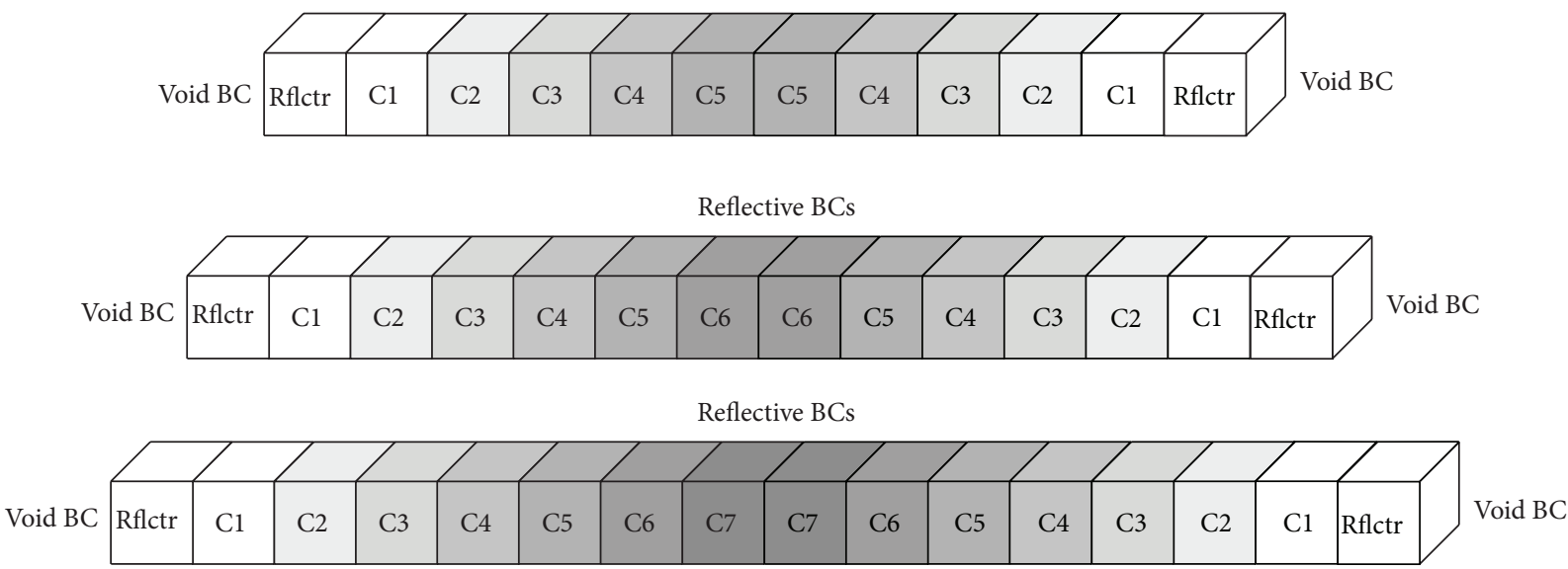

FIgURE 17: Partial 3D fuel channels with axial reflector cells developed for the study of the cells at the inlet.

Due to the geometric nature of the problem, 3D calculations are necessary here. Repetitive time consuming 3D Monte Carlo transport calculations should be avoided as much as possible during the optimization phase of the core. An alternative would be to fall back on the rapidity of deterministic codes, to handle 3D geometries (DRAGON for example). However, a performant deterministic transport calculation deals generally with a restricted number of unknowns (or number of regions in the geometry). Consequently, the objective here is to establish the smallest 3D geometry that is (in terms of number of cells) able to determine the multigroup macroscopic cell averaged cross sections in reflector cells and in fuel cells adjacent to these reflector cells with an acceptable accuracy [18].

4.1. 3D Reference Model with Axial Reflector Cells. Figure 9 illustrates the 3D fuel channel with reflector cells at both ends.
Reflective BCs are applied in the radial direction, and void $\mathrm{BCs}$ are applied in the axial direction.

The structure of the high efficiency fuel channel is maintained throughout the reflector cell, but the space normally occupied by the fuel bundle is now completely filled with coolant (or completely voided if the coolant is absent). The local conditions applied in the reflector cells are those found in the inlet and outlet cells, that is, $\mathrm{Cl}$ and $\mathrm{C} 14$, respectively, since one can assume that there will be no significant variations in temperatures and densities in the reflector cells.

4.2. Extended Simulation Strategy Model. To reduce the size of the 3D geometries, the fuel channel has first been cut into two halves. The first half has been used to study the reflector cell at the inlet and fuel cell C1. The second half has been used to study the reflector cell at the outlet and fuel cell C14.

Figure 17 shows the seven partial 3D fuel channels with axial reflector cells developed in SERPENT for the study of 


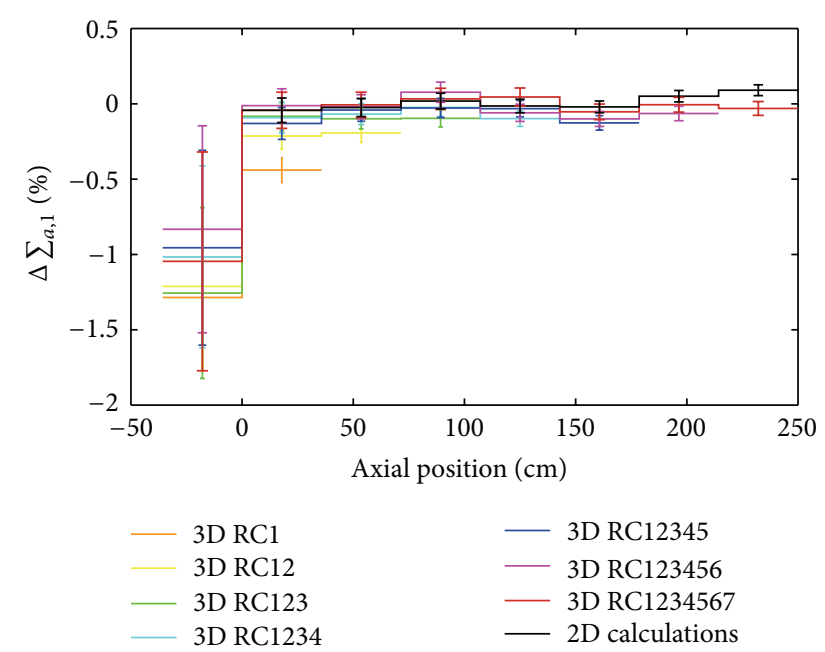

FIGURE 18: Relative differences between absorption cross sections for the fast group.

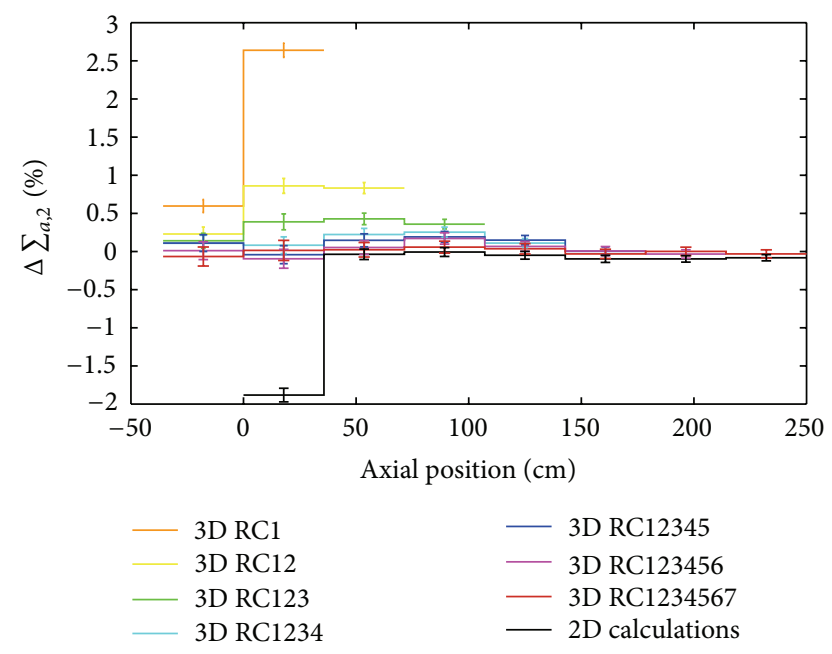

FIGURE 19: Relative differences between absorption cross sections for the thermal group.

the cells at the inlet. To close the geometries, reflective BCs are applied after the last fuel cell (Figure 17 shows the unfolded geometries). The same methodology has been applied for the cells at the outlet.

The accuracy of the partial 3D fuel channels with axial reflector cells has been evaluated by comparing along the fuel channel their multigroup cell averaged cross sections to those obtained from the complete 3D fuel channel with axial reflector cells (Figure 9). As done previously, the absorption, up and down scattering, and fission neutron production cross sections have been studied. The cross sections have been condensed to the same energy groups structure and homogenized over each cell. The accuracy of the independent 2D infinite lattice cell calculations has also been evaluated in the same way.

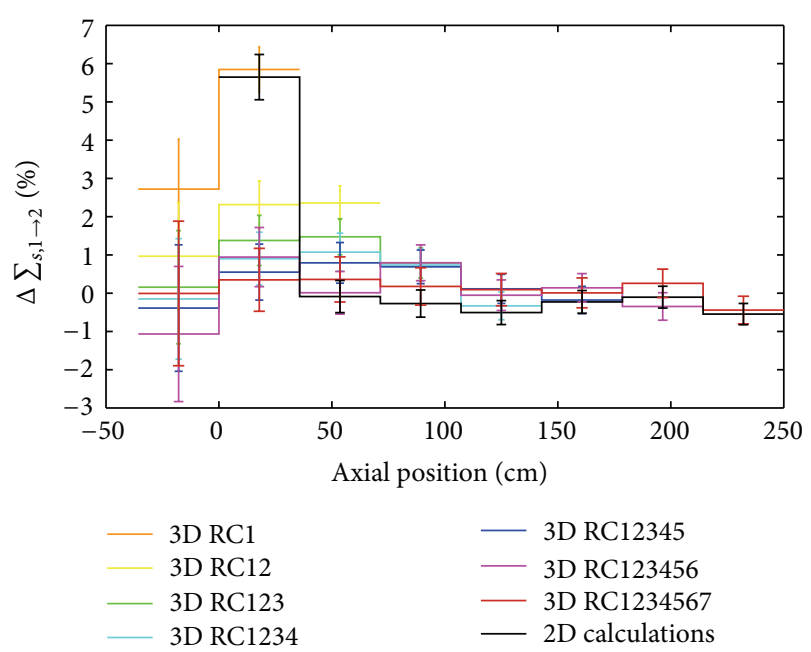

FIGURE 20: Relative differences between down scattering cross sections.

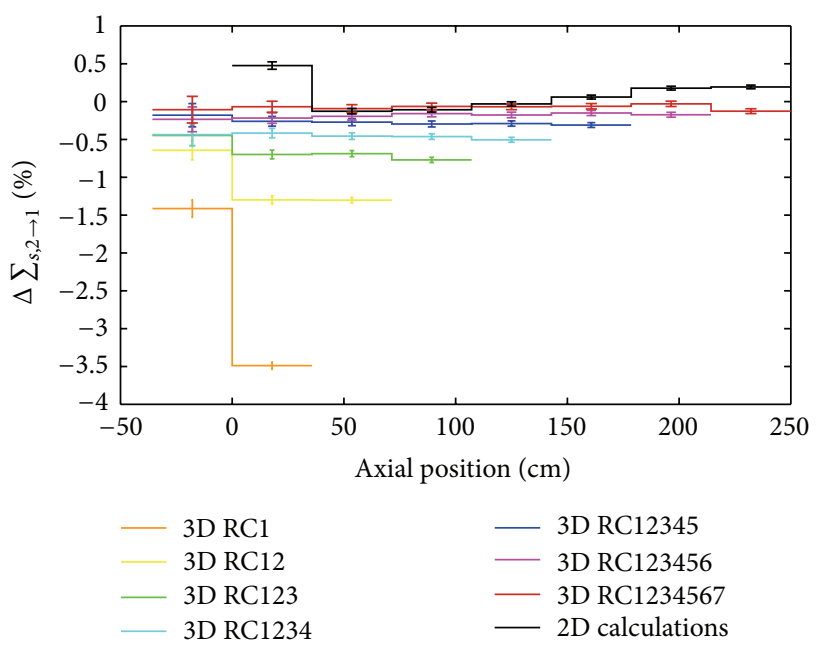

FIGURE 21: Relative differences between up scattering cross sections.

Figures 18, 19, 20, 21, 22, and 23 present the relative differences between the multigroup cell averaged cross sections calculated as follows:

$$
\Delta \Sigma_{x, g}(\%)=100 \times\left(\frac{\Sigma_{x, g}^{\text {Complete }}-\Sigma_{x, g}^{\text {Partial or 2D }}}{\Sigma_{x, g}^{\text {Complete }}}\right),
$$

where the Complete superscript refers to the complete $3 \mathrm{D}$ fuel channel (Figure 9) and the Partial or 2D refers to one of the partial 3D fuels channels (Figure 17) or to the 2D cells (Figure 4). In each figure, the legend lists the geometries studied. For example, the label "3D RCl" stands for the partial 3D fuel channel containing a reflector cell and the fuel cell C1 (top picture in Figure 17). The label "2D calculations" stands for the independent 2D infinite lattice cell calculations. Note that the reflector cell lies in the negative axial positions.

Figures 18-23 must be analyzed as follows. One must focus on one cell at a time and examine the evolution of the curves in that given cell. The objective here is to find the 


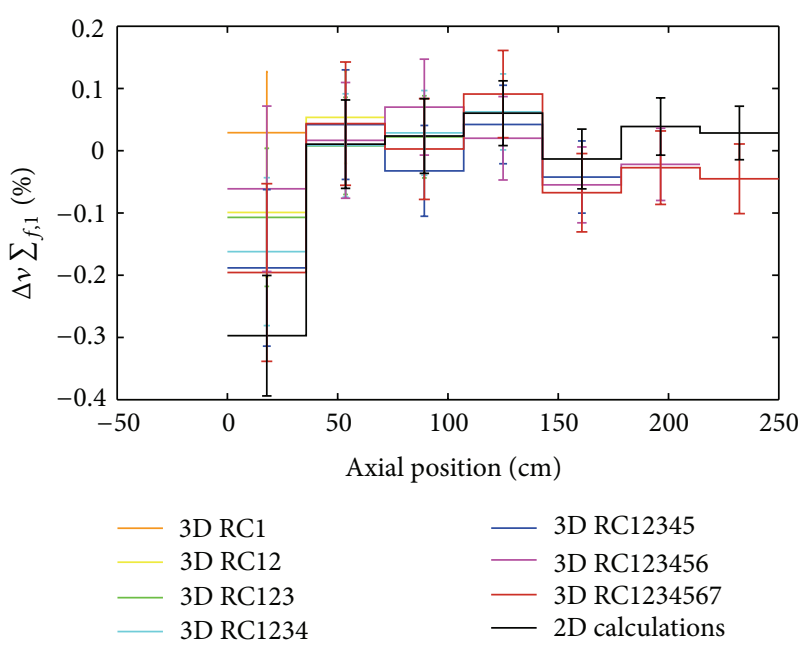

FIGURE 22: Relative differences between fission neutron production cross sections for the fast group.

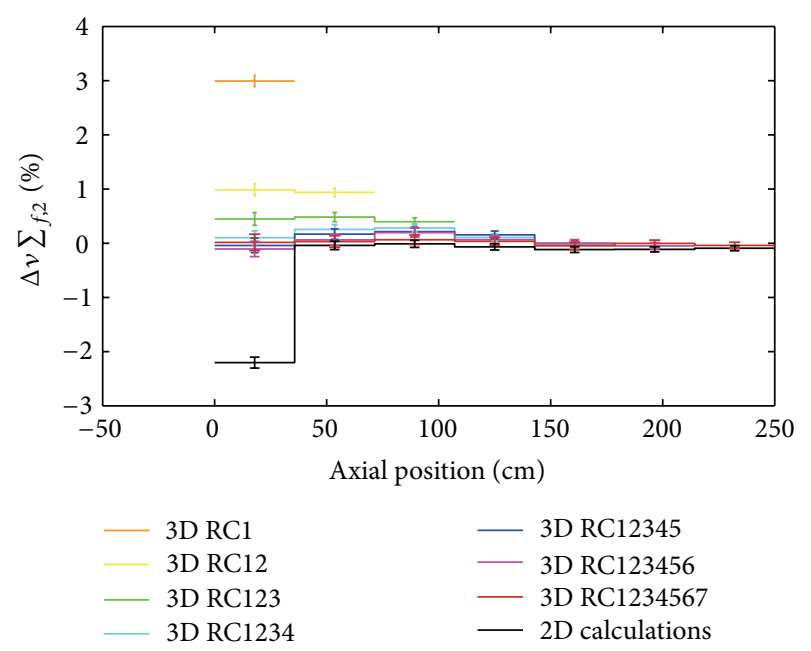

FIGURE 23: Relative differences between fission neutron production cross sections for the thermal group.

appropriate partial 3D fuel channel that reduces (in absolute value) the value of $\Delta \Sigma_{x, g}$ (in the reflector cell and in the fuel cell $\mathrm{Cl}$ in particular) to an acceptable level of accuracy considering that the geometry must be as small as possible. Ideally, $\Delta \Sigma_{x, g}$ should be equal to zero.

One can observe that there is no data coming from a $2 \mathrm{D}$ calculation in the reflector cell. As mentioned above, this is expected because it is not possible to perform neutron transport calculation without neutrons sources. In addition, it is normal to observe that the partial 3D fuel channels do not show data on all axial positions. For example, the model labeled "RCl" presents only two values located between $-35.71 \mathrm{~cm}$ and $35.71 \mathrm{~cm}$ (for the reflector cell and the fuel cell C1) because the fuel cells C2, C3, C4, C5, C6, and C7 do not exist in this geometry. Also note that for the fission production cross sections, no information is provided for the reflector cell, since it does not contain fissile material.
TABLE 2: Channel multiplication factors and CVRs for models with axial reflector cells.

\begin{tabular}{lccc}
\hline Model & $k_{\text {eff }}^{\text {cooled }}$ & $k_{\text {eff }}^{\text {voided }}$ & CVR $(\mathrm{mk})$ \\
\hline \multicolumn{3}{l}{$\begin{array}{l}\text { Reference } \\
\text { with reflector }\end{array}$} & Void axial BCs \\
$\begin{array}{l}\text { cells } \\
\begin{array}{l}\text { Extended } \\
\text { strategy }\end{array}\end{array}$ & $1.21277 \pm 0.00004$ & $1.19960 \pm 0.00005$ & $-9.05 \pm 0.06$ \\
\hline
\end{tabular}

In general, $\Delta \Sigma_{x, g}$ approaches zero when more fuel cells are added in the partial 3D fuel channel. Also, Figures 1823 highlight the fact that the independent $2 \mathrm{D}$ infinite lattice cell calculations do not provide a good evaluation of the multigroup cell averaged cross sections in the fuel cell $\mathrm{C} 1$ located between $0 \mathrm{~cm}$ and $35.71 \mathrm{~cm}$. Based on these results, the best compromise between accuracy of the results and simplicity of the 3D geometry consists in selecting the four fuel cells model labeled "RC1234." The same behavior is also observed at the outlet where only the four last fuel cells are needed.

Following this study, the extended simulation strategy for fuel channels with axial reflector cells is divided into the following three steps.

(i) Two 3D calculations with SERPENT, one for the channel inlet from a partial 3D fuel channel containing the inlet reflector cell and the four first fuel cells (fourth picture from the top in Figure 17) and the second one for the channel outlet from a partial 3D fuel channel containing the outlet reflector cell and the four last fuel cells in order to generate the multigroup cell averaged cross sections in the two reflector cells and in the fuel cells $\mathrm{Cl}$ and $\mathrm{Cl} 4$.

(ii) Twelve independent 2D infinite lattice cell calculations (Figure 4) with SERPENT in order to generate the multigroup cell averaged cross sections in the fuel cells $\mathrm{C} 2$ to $\mathrm{C} 13$.

(iii) Using the cross sections calculated in the two first steps, a single 1D calculation (from a geometry similar to Figure 5 but with a 1D reflector cell at both ends) is performed with DRAGON in order to calculate the global properties of the fuel channel.

4.3. Models Comparison. Table 2 presents a comparison of the multiplication factors and CVRs obtained from the 3D reference model with axial reflector cells (SERPENT 3D) (Figure 9) and the extended simulation strategy model (SERPENT 3D + SERPENT 2D + DRAGON 1D). Here, only the situation with void axial BCs was considered.

By comparing Tables 1 and 2, one can observe that, for void axial BCs, the CVRs obtained from models with axial reflector cells are smaller (in absolute value) than those obtain from models without axial reflector cells. This observation can be explained in part by the fact that the reflector cells reflect some neutrons back in the system, leading therefore to higher multiplication factors. 
The extended simulation strategy shows good agreement with the $3 \mathrm{D}$ reference model with axial reflector cells.

\section{Conclusion}

The simulation strategy proposed for the evaluation of the neutronic properties of a Canadian SCWR fuel channel is able to take into account all axial profiles in a single general model. It has been shown, for the cases studied, that a $3 \mathrm{D}$ calculation is equivalent to a series of isolated $2 \mathrm{D}$ calculations followed by a single $1 \mathrm{D}$ calculation. From this fact, most of the calculations can be done very easily. The modeling of the axial reflector still requires $3 \mathrm{D}$ calculations. However, the size of these calculations has been reduced considerably.

To conclude, the simulation strategy proposed could reduce the computation time by a factor of about 600 . In our case, a 3D Monte Carlo simulation takes approximately 15 hours for one burnup step. For standard deterministic codes, fourteen 2D infinite lattice cell calculations take approximately 1.5 minutes in total, and a $1 D$ calculation takes a few seconds, and this for each burnup step. This deterministic calculation strategy will be investigated in future work.

\section{Acknowledgments}

This work was supported in part by the NSERC/NRCan/ AECL Generation IV Energy Technologies Program, the Fonds québécois de la recherche sur la nature et les technologies (FQRNT), and the Canadian Nuclear Society (CNS).

\section{References}

[1] "U.S. DOE Nuclear Energy Research Advisory Committee and the Generation IV International Forum, A technology roadmap for Generation IV Nuclear Energy Systems, GenIV International Forum," 2002, http://www.gen-4.org/ Technology/roadmap.htm.

[2] D. F. Torgerson, B. A. Shalaby, and S. Pang, "CANDU technology for Generation III+ and IV reactors," Nuclear Engineering and Design, vol. 236, no. 14-16, pp. 1565-1572, 2006.

[3] L. K. H. Leung, "Developing the Canadian SCWR concept for addressing GIF technology goals," in Proceedings of the 3rd China-Canada Joint Workshop on Supercritical-Water-Cooled Reactors (CCSC '12), Shanxi, China, April 2012.

[4] P. G. Boczar, W. Shen, J. Pencer, B. Hyland, P. S. W. Chan, and R. G. Dworschak, "Reactor physics studies for a pressure tube supercritical water reactor (PT-SCWR)," in Proceedings of the 2nd Canada-China Joint Workshop on Supercritical WaterCooled Reactors (CCSC '10), Toronto, Ontario, Canada, April 2010.

[5] J. Shan, W. Chen, B. W. Rhee, and L. K. H. Leung, "Coupled neutronics/thermal-hydraulics analysis of CANDU-SCWR fuel channel," Annals of Nuclear Energy, vol. 37, no. 1, pp. 58-65, 2010.

[6] P. Yang, L. Cao, H. Wu, and C. Wang, "Core design study on CANDU-SCWR with 3D neutronics/thermal-hydraulics coupling," Nuclear Engineering and Design, vol. 241, no. 12, pp. 4714-4719, 2011.

[7] D. Altiparmakov, "New capabilities of the lattice code WIMSAECL," in Proceedings of the International Conference on the
Physics of Reactors (PHYSOR '08), Interlaken, Switzerland, September 2008.

[8] G. Marleau, R. Roy, and A. Hébert, "A user guide for DRAGON 3.06," Tech. Rep. IGE-174 Rev. 8, Institute of Nuclear Engineering, École Polytechnique de Montréal, Montréal, Québec, Canada, 2009.

[9] J. Leppänen, PSG2/SERPENT - A Continuous-Energy Monte Carlo Reactor Physics Burnup Calculation Code, VTT Technical Research Centre of Finland, Espoo, Finland, 2011.

[10] C. K. Chow and H. F. Khartabil, "Conceptual fuel channel designs for CANDU-SCWR," Nuclear Engineering and Technology, vol. 40, no. 2, pp. 139-146, 2008.

[11] M. H. McDonald, B. Hyland, H. Hamilton et al., "Preconceptual fuel design concepts for the Canadian super critical water-cooled reactor," in Proceedings of the 5th International Symposium on Supercritical Water-Cooled Reactors (ISSCWR5), Vancouver, British Columbia, Canada, March 2011.

[12] M. Magill, J. Pencer, R. Pratt, W. Young, G. W. R. Edwards, and B. Hyland, "Thorium fuel cycles in the CANDU supercritical water reactor," in Proceedings of the 5th International Symposium on Supercritical Water-Cooled Reactors (ISSCWR-5), Vancouver, British Columbia, Canada, March 2011.

[13] W. Shen, "Assessment of the applicability of the traditional neutron-diffusion core-analysis method for the analysis of Super CriticalWater Reactor (SCWR)," in Proceedings of the Advances in Reactor Physics-Linking Research, Industry and Education (PHYSOR '12), Knoxville, Tenn, USA, 2012.

[14] X. Wang and J. Pencer, "Assessment of reactor core simulations using DONJON for a 2-dimensional SCWR Benchmark Core," in Proceedings of the 20th International Conference on Nuclear Engineering (ICONE-20), Anaheim, Calif, USA, July-August 2012.

[15] G. Harrisson and G. Marleau, "2-D and 3-D evaluation of neutronic properties along a Canadian SCWR fuel channel," in Proceedings of the 3rd China-Canada Joint Workshop on Supercritical-Water-Cooled Reactors (CCSC '12), Shaanxi, China, April 2012.

[16] M. Varvayanni, P. Savva, and N. Catsaros, "Aspects of cell calculations in deterministic reactor core analysis," Annals of Nuclear Energy, vol. 38, no. 2-3, pp. 185-193, 2011.

[17] E. Fridman and J. Leppänen, "On the use of the Serpent Monte Carlo code for few-group cross section generation," Annals of Nuclear Energy, vol. 38, no. 6, pp. 1399-1405, 2011.

[18] M. Blaise, Étude de l'interface coeur-réflecteur Application au calcul du réflecteur lourd [Ph.D. thesis], Université Paris XI Orsay, Paris, France, 1993. 


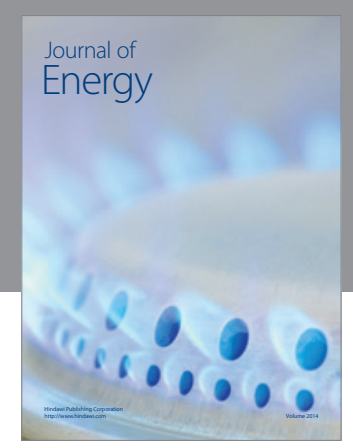

Journal of

Industrial Engineering
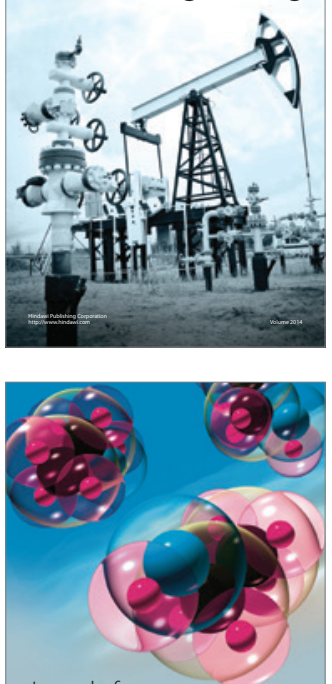

Fuels
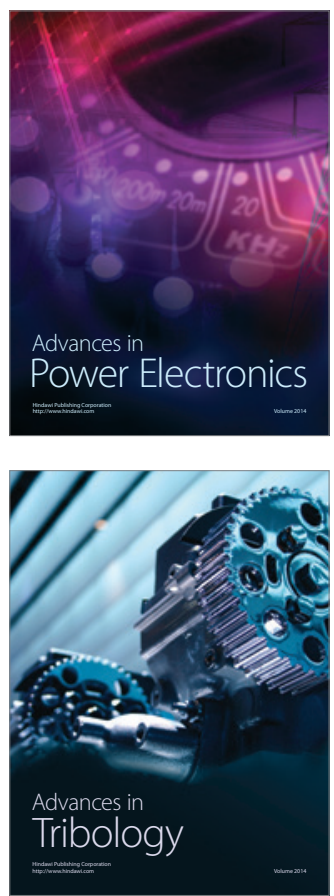

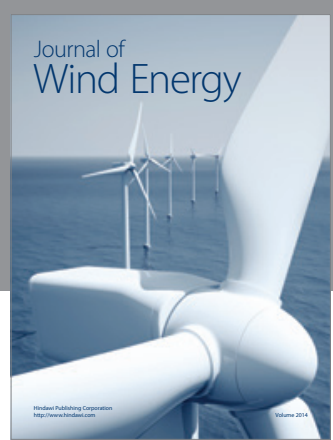

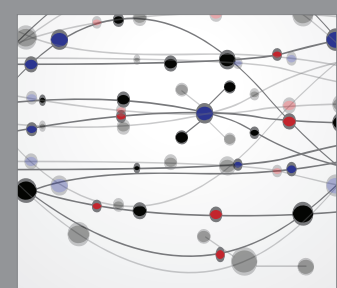

The Scientific World Journal

Submit your manuscripts at http://www.hindawi.com

Journal of

Structures
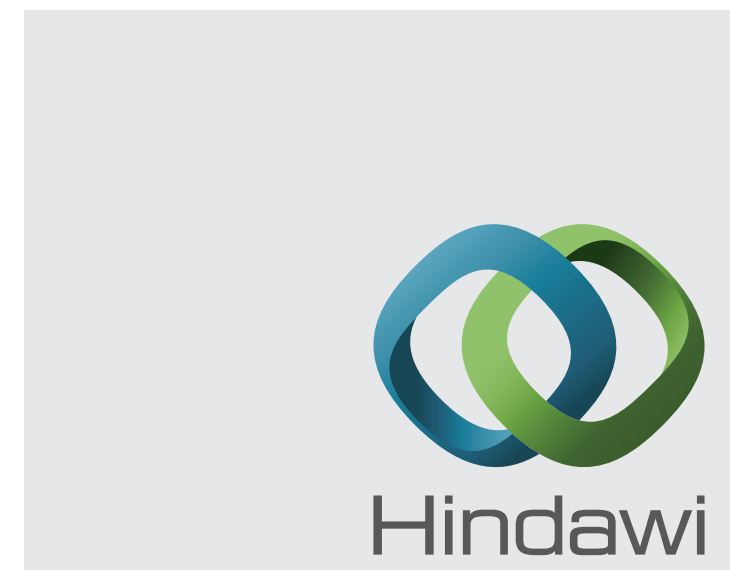

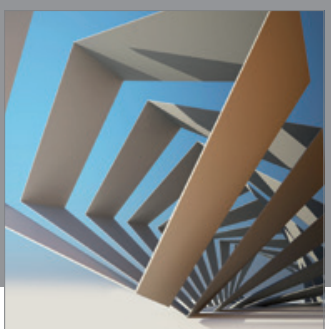

Rotating

Machinery
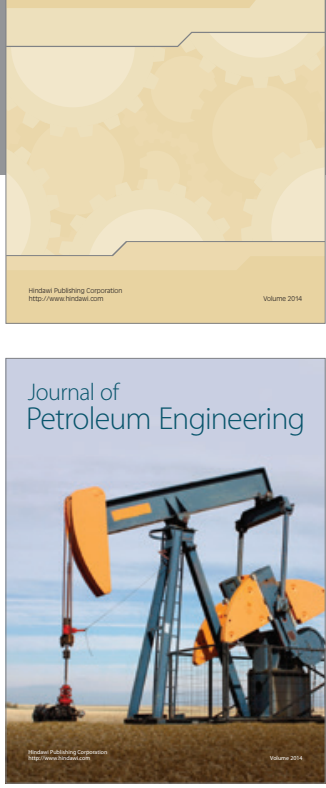

Journal of

Solar Energy
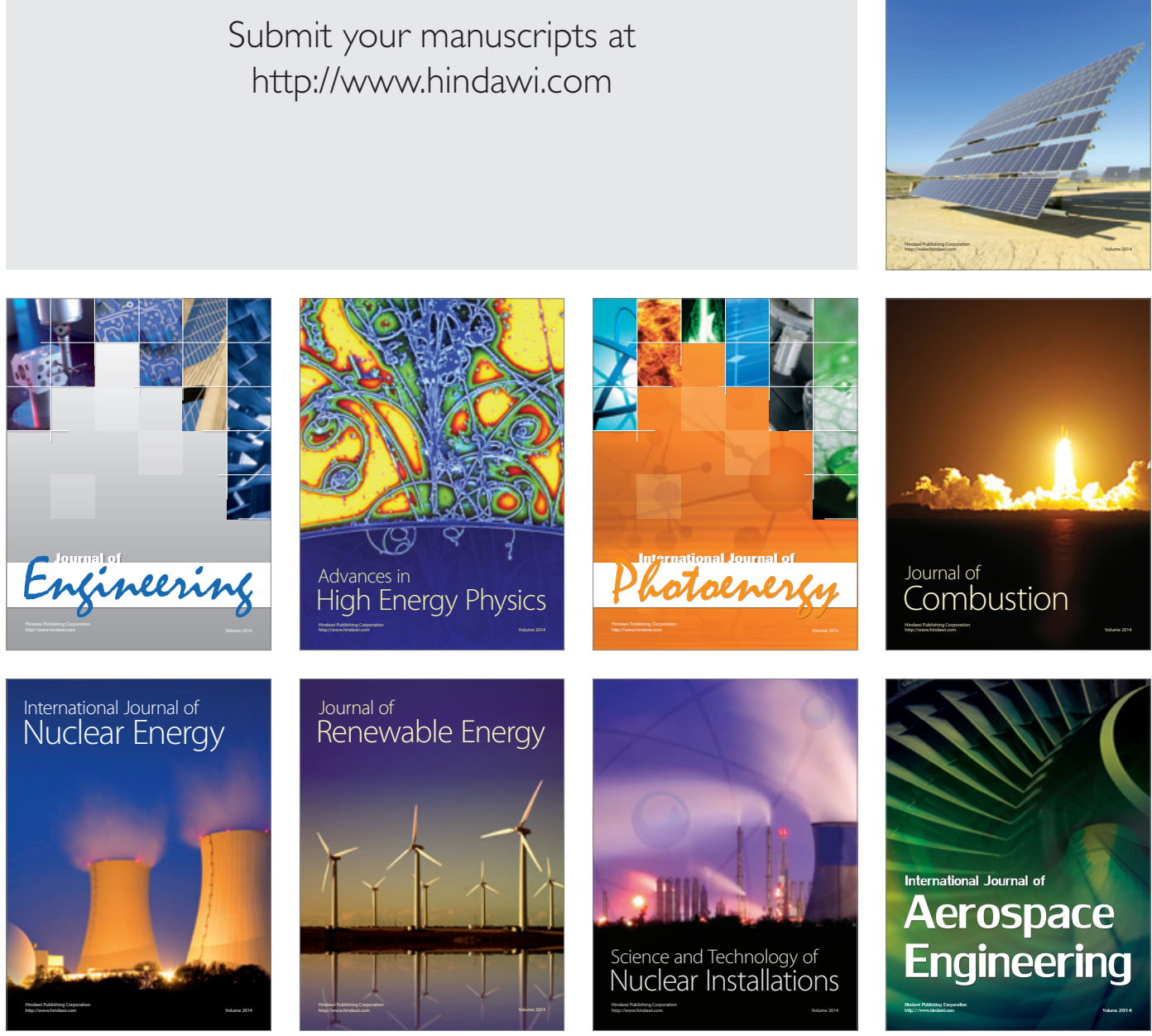